\title{
Factors Affecting MOOCs' Adoption in the Arab World: Exploring Learners' Perceptions on MOOCs' Drivers and Barriers
}

\author{
Nahed F. Abdel-Maksoud ${ }^{1}$ \\ ${ }^{1}$ College of Education, Damietta University, Damietta, Egypt \\ Correspondence: Nahed F. Abdel-Maksoud, College of Education, Damietta University, Damietta, Egypt.
}

Received: July 17, 2019

doi:10.5539/ies.v12n11p164
Accepted: August 22, $2019 \quad$ Online Published: October 28, 2019

URL: https://doi.org/10.5539/ies.v12n11p164

\begin{abstract}
Despite the potentials promised by MOOCs to democratize education, the adoption rate of MOOCs is still low in certain parts of the world, including the Arab region. Research on MOOCs' adoption in the Arab region is also limited. To fill this research gap, this quantitative study aims to explore Arab learners' perceptions on the influential drivers and barriers of MOOCs' usage. Participants of the study were 821 learners, all from Arabic-speaking countries, who were registered in at least one MOOC offered by one of the biggest Arabic MOOC platforms, Rwaq, during the year 2019. Data were collected using a web-based survey. Results indicated that participants were overall satisfied with their MOOC experience. The main reasons behind their enrolling in MOOCs were: they wanted to learn new things; they thought MOOCs were interesting; they needed credentials for their CVs. The main benefits they cited for participating in MOOCs were: the material learned through MOOCs was valuable to me, the MOOCs' structure and learning activities were flexible and supported my learning, Participating in MOOCs developed my technological competency. The main MOOC barriers were: problems accessing MOOCs materials due to unreliable internet connection, not having enough time to complete all required tasks and assignments, lacking the proficiency to use different tools in MOOCs, and the instructor was not there to help. Other findings of the study: gender, age, academic levels were not correlated with learners' satisfaction with MOOCs. On the other hand number of MOOCs previously completed was significantly related to learners' satisfaction in MOOCs.
\end{abstract}

Keywords: MOOCs, MOOC satisfaction, MOOCs drivers, MOOCs barriers, learners' perceptions, Arab MOOCs providers, Rwaq

\section{Introduction}

Massive Open Online Courses (MOOCs) have gained significant attention from educators and learners all over the world. In their 2018 vision report, MOOCWATCH reported that the MOOC movement reached a total of 101 million learners in 2018 (Class Central, 2018). The reason behind this popularity is that MOOCs can reach large numbers of learners. Anyone with internet access at any part of the world can take courses from the world's prominent universities. Since they are usually free, MOOCs are cost-efficient substitute for formal education and especially for learners in underserved areas where access to quality educational resources are limited (Kennedy, 2014). By helping learners in developing countries access high-quality instructional materials (Barclay \& Logan, 2013), MOOCs promise to address the issue of equity in education. However, much of the promised potentials for MOOCs in underserved regions of the world remain unproven. Many claims about MOOCs are based on anecdotal evidence from Western contexts (Pappano, 2012). Taking into account the difference in learners and learning contexts between the industrialized countries, and the developing countries, there is a need to focus more on how MOOCs are implemented in the developing countries' contexts (Castillo, Lee, Zahra, \& Wagner, 2015).

Despite all these promises and potentials, MOOCs haven't lived to their expectations for many reasons. First, the dropout rates for MOOCs' learners are very high. Enrollment rates typically decrease over time after the MOOC is launched, and the completion rate is still very low. Second, MOOCs, which are mainly high quality online courses offered by prestigious universities, need solid academic background. As a result, most MOOCs' participants are usually college students from developed countries. Thus, the goal of educating the masses has not yet been realized. Third, the adoption of MOOCs has been relatively low especially in certain regions. A large majority of MOOCs' participants comes from North America and Europe. There is very limited participation from Asia and even less from Africa. Moreover, Kizilcec and Halawa (2015) reported that learners in Asia, Africa, and Latin 
America were only half as likely to persist in MOOC learning as those in Northern America and Europe.

\section{Problem}

Overall, the adoption of MOOCs is not as widespread as expected, especially in certain regions. MOOCs were mainly initiated to democratize education, and offer free high quality courses to people around the world, and especially marginalized groups in some cultures. However, there are a number of challenges that inhibit MOOCs from attaining their potentials in many parts of the world, which already have issues of access to high quality education. Therefore, understanding the factors affecting MOOCs adoption in those areas will be insightful.

Research on adoption of MOOCs in developing countries is very limited (Liyanagunawardena, Adams, \& Williams, 2013; Barclay \& Logan, 2013). Most MOOC research is located in North America and Europe (Veletsianos \& Shepherdson, 2016). In the Arab region, there is still paucity of research done on MOOCs.Veletsianos and Shepherdson (2016) reported that only 4 authors $(0.8 \%)$ were affiliated with institutions from the Middle East, as compared to about (50\%) of the authors were affiliated with institutions from the USA and (10\%) from the United Kingdom, (7.7\%) from Australia, (5.4\%) from China, (4.8\%) from Spain, (4.5\%) from Canada, and $(2.2 \%)$ from Germany. This indicates that MOOCs research is concentrated in a few geographic regions.

Paucity of research done on MOOCs in the Arab region reflects the low percentage of MOOCs participants in this region. Such low learning participation statistics creates concerns, and are considered obstacles that weaken MOOCs' sustainability and effectiveness (Hollands \& Tirthali, 2014). Low MOOCs enrollment and participation rates in the Arab region can be attributed to the fact that people there speak Arabic, and the majority of the MOOCs today are run in English. Not many people are competent in a second language to the level to take up an online course (Liyanagunawardena et al., 2013). Again, access to digital technologies in parts of the Arab countries is still insufficient to support online learning (Liyanagunawardena, 2012). Computer literacy is another factor that inhibits the participation in MOOCs in the Arab countries.

To sum up, MOOCs adoption in the Arab world has been low due to computer literacy, insufficient access to digital technologies, and language related issues. However, this is slowly changing due to the spread of internet access in the region, the digital generation that knows how to handle technology, and the evolution of Arabic platforms like Rwaq, Edraak, and EgyMOOCs, which offer their courses in Arabic. This study seeks to explore Arab users' satisfaction with their experience on MOOCs, and their perceptions' on the factors that help / hinder MOOC adoption. Understanding these factors is important to promote MOOCs in this region. The insights gained from this study would offer suggestions and guidelines to support the diffusion of MOOCs, and would aid in overcoming the potential barriers of MOOCs adoption among learners in the Arab region who are constrained by social and economic settings.

\section{Significance of the Study}

MOOCs adoption is new to the Arab region. Very few research studies were conducted to address the topic of MOOCs drivers and barriers in the Arab world. Understanding drivers and barriers of MOOC adoption is highly important to promote the diffusion of MOOCs in this region. Learners' perceptions are an important consideration for MOOCs' providers and instructors when making decisions about the instructional materials, strategies and pedagogies employed in MOOCs. In addition, the findings of this study are believed to provide additional empirical evidence pertaining to learners' perceptions and expectations in MOOCs. By extending analysis to include demographic traits, such as age, gender, educational level, and how they relate to MOOCs' satisfaction, the findings of this study are believed to be of value to MOOCs' researchers, providers and instructors.

\section{Research Questions}

This study seeks to answer the following questions:

1) How satisfied are Arab learners with their MOOCs experience?

2) What are the drivers (benefits) of MOOCs from the perspective of Arab learners?

3) What are the barriers to MOOCs from the perspective of Arab learners?

4) Do factors: age, gender, academic level, number of MOOCs previously completed, affect learners' satisfaction in MOOCs?

\section{Relevant Literature}

\subsection{What Are MOOCs?}

Massive Open Online Courses (MOOCs) are high-quality, open-access online courses, free of charge, and 
accessible at anytime, anywhere, and by anyone who has internet access. MOOCs usually have a syllabus with specific objective, a calendar, and a discussion forum, some teaching materials, mainly videos, some activities, some quizzes and exams (Abdel-Maksoud, 2019). A MOOC is massive in the sense that it is usually designed to accommodate large numbers of students that could reach 100,000 students. A MOOC is online, so it can be remotely accessed from anywhere in the world, by anyone who has internet access. A MOOC is open in the sense that it is always free, and it does not require certain prerequisites. And finally, a MOOC is a course which means that it should have the same components as any course, objectives, activities, exams, and some form of interaction among students, and between students and instructor.

\subsection{Theoretical Framework of MOOCs}

MOOCs originally emerged from the work of the scholars George Siemens and Stephen Downes who in 2008 started teaching a series of MOOCs on "Connectivism and Connected Knowledge", which served as a test ground for their theories on "Connectivism" and "Connected knowledge" (Siemens, 2013; Downes, 2012; Downes, 2008). Siemens (2013) proposed that there are two types of MOOCs, first: cMOOCs or, Connectivist MOOCs that emphasize collaborative or connected learning. (cMOOCs). This type of MOOCs is built on Connectivism theory, which views knowledge as a social construct that is promoted by social networking, collaboration, participants' engagement and self-direction. This theory argued that connectivist learning is based on four key principles: "autonomy, diversity, openness, and connectedness/interactivity" (Milligan, Littlejohn, \& Margaryan, 2013, 150). All four principles are present in MOOCs.

The second type of MOOCs proposed by Siemens (2013) is called xMOOCs. xMOOCs employ a cognitive-behaviorist or instructivist pedagogical approach. They are based on the paradigm of transferring knowledge to learners, focusing on learning content, and individual learning, rather than learning in groups. xMOOCs in that sense are considered an extension of the traditional online courses, and this type of MOOCs is the type developed and introduced by traditional universities like Stanford, MIT / Harvard, etc. (Vidalgo-Blanco, Sine-Ichloz, \& Garcia-Benalvo, 2016; Ng \& Widom, 2014).

\subsection{Research on MOOC Adoption}

Research on MOOC adoption can be classified into two main categories: MOOC drivers, and MOOC barriers. As for MOOC drivers, characteristics of learners and the quality of video lectures were highly correlated with MOOCs' adoption and persistence (Evans, Baker, \& Dee, 2016). Research also found that the main factors associated with MOOC adoption are self-directed ability, critical literacy, and social presence of instructor (Kop, 2011). Perceived usefulness, self-regulation and gender were also found to be key predictors of MOOCs adoption (Ma \& Lee, 2019). Video lectures' views were also strong predictors of MOOC completion (Pursel, Zhang, Jablokow, Choi \& Velegol, 2016). System quality, performance expectancy, and Computer self-efficacy were also found to be significant predictors of MOOC adoption (Fianu, Blewett, Ampong, \& Ofori, 2018).

As for the barriers of MOOC adoption, research found that language problems, time constraints and technology skills were the main barriers of MOOC adoption (Fini, 2009). Lack of incentive, failure to understand the content, lack of instructions, and having other priorities were also reported to be the main reasons behind MOOC dropout (Hew \& Cheung, 2014). Other barriers to MOOC adoption include subject knowledge, level of education, and insufficient experience with MOOCs (Semenova \& Rudakova, 2016). Other factors associated with MOOC dropout are: course structure and content, self-paced or not, workload and duration, course topic, type of exams, type of assessments and feedback, and interaction with students and instructors, etc. (Adamopoulos, 2013). It is worth noting that some studies found significant differences among learners from various regions. Gameel and Wilkins (2019), for example, who surveyed 2882 learners enrolled in five English and Arabic MOOCs, found that learners in certain regions have significantly higher skills than learners in other regions. Moreover, male learners from three of the five regions examined have higher levels of engagement than female learners. These findings have important implications for MOOCs' developers and researchers.

\subsection{MOOCs in the Arab Region}

Elite universities with their aggregators like Coursera, edX, Udacity, etc., have led MOOC development to the present. However, these providers did not offer localized content to suit the needs of specific populations (Baggaley, 2014). Most MOOCs were offered in English. As a result, only a few group of people who master English language were able to benefit from existing MOOCs. This situation started to change when Rwaq, the first Arab online learning platform was launched in September 2013 by a Saudi entrepreneur Fouad Al-Farhan, and his friend, Sami Al-Hussayen, to provide online educational courses in Arabic language in various disciplines. Edraak, another MOOC portal for the Arab world, was launched in 2014 as an outcome of an agreement between edX, and Queen Rania Foundation in Jordan (Hazlett, 2014; Pirkle, 2014). Shortly after that, 
similar projects such as MenaVersity in Lebanon and SkillAcademy, and EgyMOOCs in Egypt have been launched. All these portals provide free online courses in Arabic language to a large population of Arab countries, who have adequate computer literacy, and who have internet access. Nevertheless, there is still a gap between the potentials of MOOCs and their actual use to enhance lives within the Arab world.

MOOCs offer an educational opportunity to those who cannot attend higher education institutions due to financial or other considerations. However, in many regions in the Arab world there is still a problem in digital access. Many people there still do not have access to computer or internet connection. Besides, time is always an issue for working persons who cannot afford to leave work in order to study. In addition, MOOCs are always criticized for high dropout rate, which can reach 90\% or more (Watson, Watson, Yu, Alamri, \& Mueller, 2017; Jordan, 2014; Hew \& Cheung, 2014), high development costs, and enrollment data that showed that MOOC participants were primarily well educated graduates, who have strong background on the topics of MOOCs (Fischer, 2014; Hill, 2013; Selingo, 2014).

In sum, MOOCs are technological and pedagogical innovation that helped expand higher education opportunities to more people, anywhere in the world. But if they are to be successfully implemented to achieve equity in education, whether as stand-alone courses, or integrated into the current traditional courses, more and more research is needed. The aim of the present study is to explore the factors that influence the adoption of MOOCs in the Arab region. This study focuses its investigation on the Arab world for two reasons: First there is a paucity of research done on MOOCs in the Arab region. Second, the conditions in the Arab region such as lack of quality learning resources, and insufficient infrastructure may provide opportunities or pose challenges to MOOC adoption. It is hypothesized that the drivers and barriers influencing MOOCs adoption between developed countries and developing countries are different. Therefore, this study aims to explore Arab leraners' perceptions on MOOCs drivers and barriers in Arab countries?

\section{Method}

\subsection{Research Design}

This study employed the quantitative design to explore learners' perceptions of MOOCs drivers and barriers, and their satisfaction with MOOC experience.

\subsection{Participants' Characteristics}

Participants in this study were 821 learners enrolled in one or more courses offered by Rwaq platform. All participants are from Arab countries, and Arabic is their native language. Participants were recruited to fill in a web-based survey, prepared by the researcher, and sent by Rwaq. Table 1 shows the demographics of the participants.

Table 1. Demographics of the study sample

\begin{tabular}{lcc}
\hline Demographics & No. & Percentage \\
\hline Gender & 399 & $48.60 \%$ \\
Male & 422 & $51.40 \%$ \\
Female & & \\
Age (years) & 223 & $27.16 \%$ \\
18-25 years & 315 & $38.37 \%$ \\
26-35 years & 241 & $29.35 \%$ \\
$36-45$ years & 42 & $5.12 \%$ \\
$46-55$ years & 0 & $0 \%$ \\
56 or more years & & \\
Academic Level & 184 & $22.41 \%$ \\
Some secondary school certificate & \\
Bachelor & 512 & $62.36 \%$ \\
Master Degree & 98 & $11.94 \%$ \\
Doctoral Degree & 27 & $3.29 \%$ \\
Other & & \\
\hline
\end{tabular}

Figures 1 to 5 show the characteristics of the study sample. 


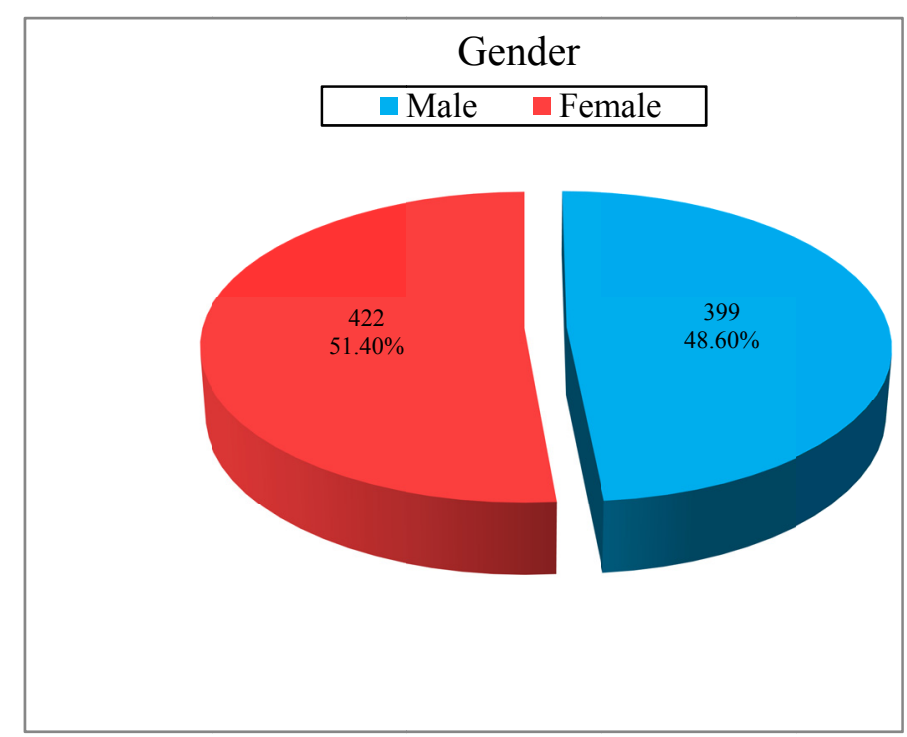

Figure 1. Sample distributed by gender

As shown in Figure 1, $51.40 \%$ of the respondents were females, whereas $48.60 \%$ were males

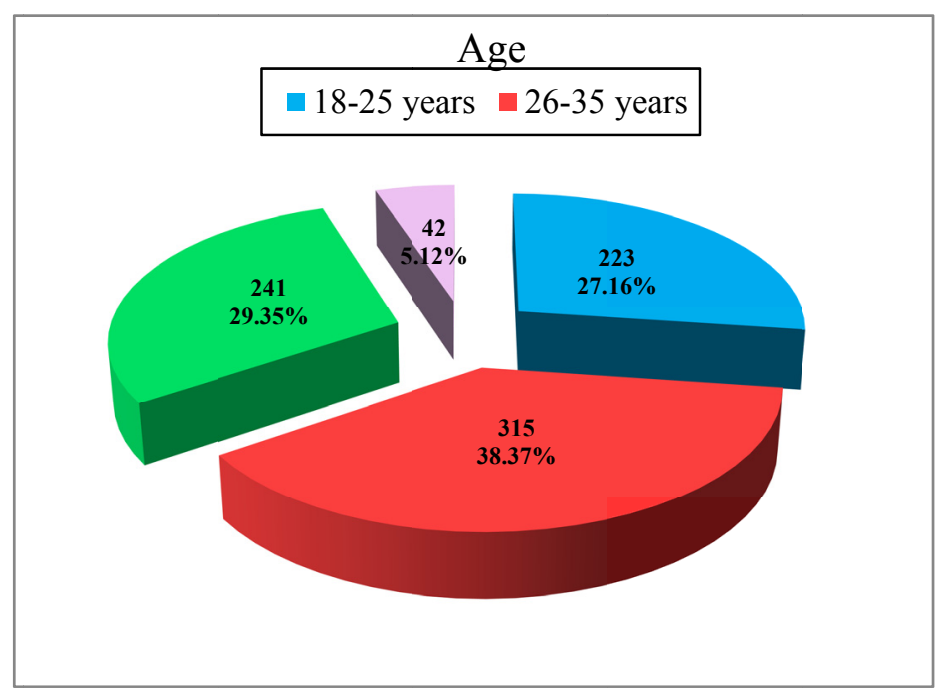

Figure 2. Sample distributed by age

Figure 2 shows that the biggest number of the study sample was in the age range of $26-35$, followed by the age range $36-45$. 


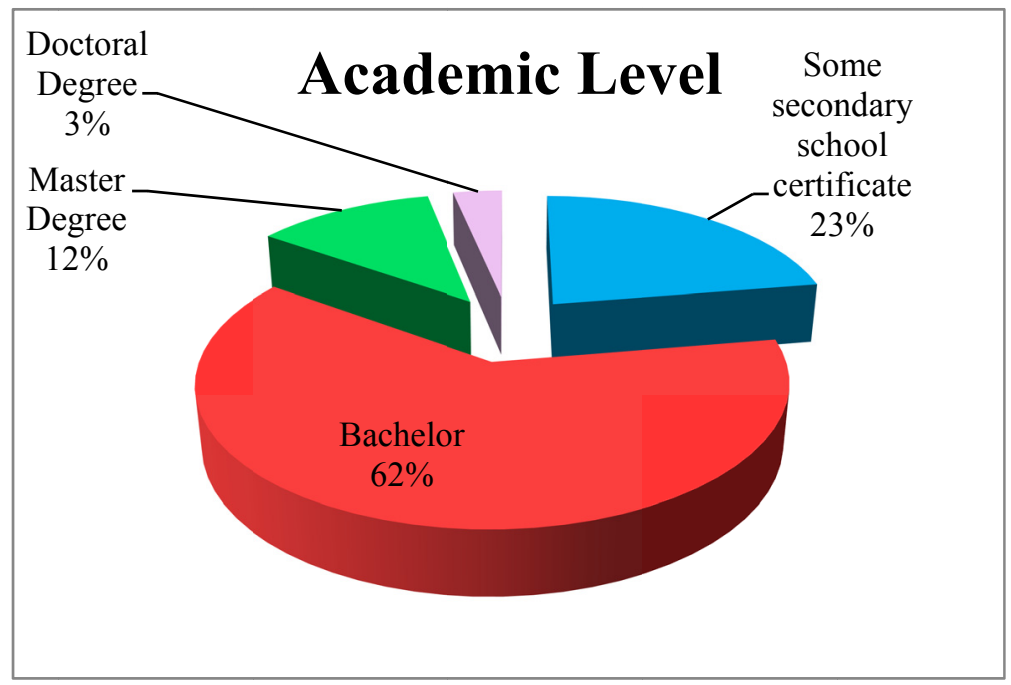

Figure 3. Sample distributed by academic level

Figure 3 indicates that the majority of the study sample (62.36\%) is college graduates who hold a Bachelor degree. The second largest group (22.41\%) holds some secondary school certificate. The least number (3.29\%) was from doctoral degree holders.

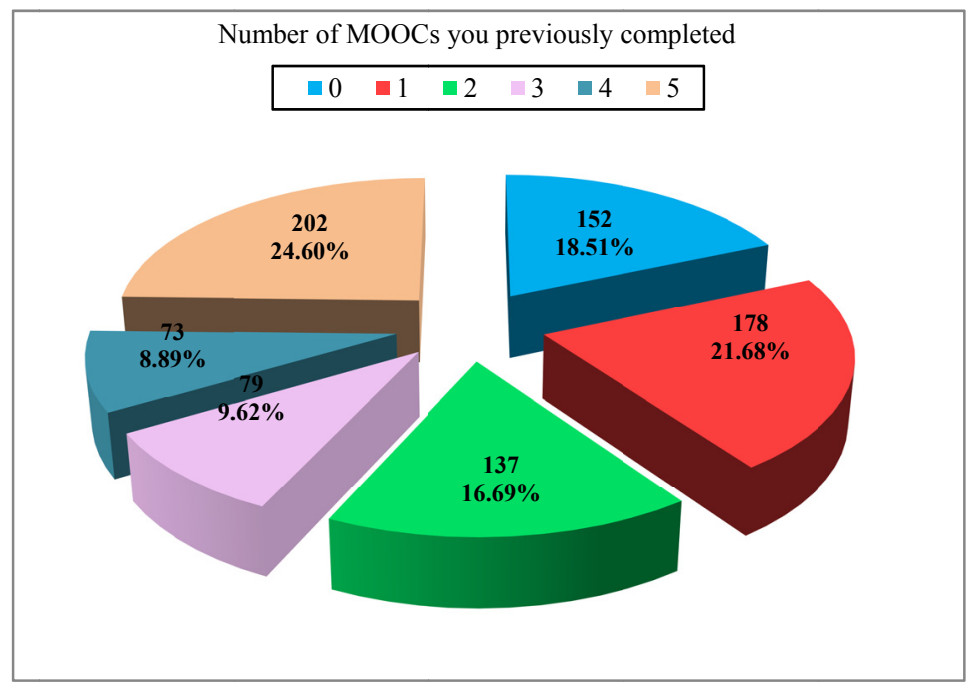

Figure 4. Sample distributed by number of moocs completed

As shown in Figure 4, the number of MOOCs previously completed vary among the sample of the study. $24 \%$ of the study sample completed 5 or more MOOCs. $21.68 \%$ completed 2 MOOCs, while $18.51 \%$ never completed a MOOC before. 


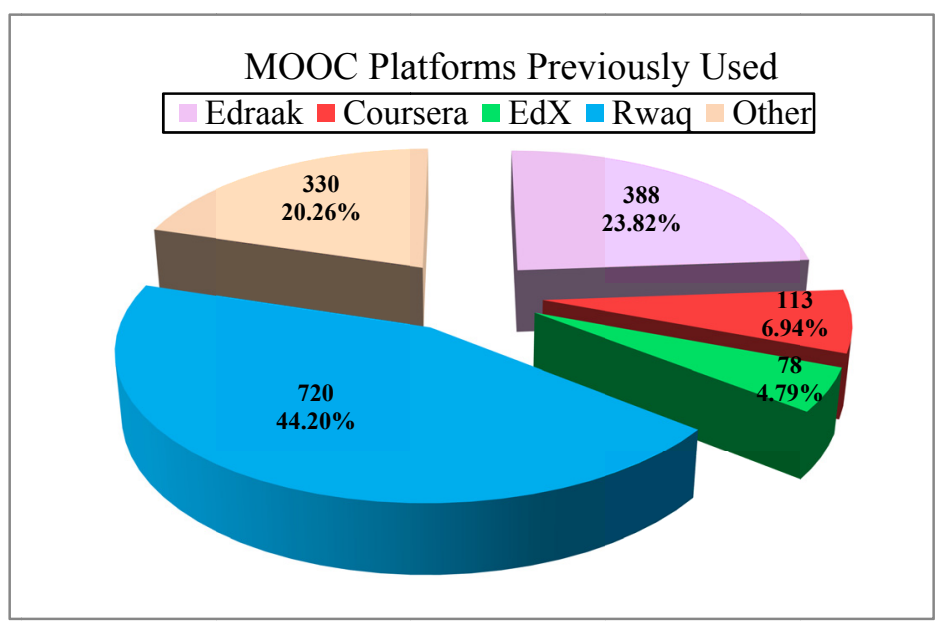

Figure 5. Sample distributed by platforms used

Figure 5 shows that the most frequently used platforms by the study sample were Rwaq (44.20\%), and Edraak $(23.82 \%)$, this can be attributed to the fact that these two platforms are the first platforms that are oriented to the Arabic-speaking audience. Platforms like Coursera (6.94\%) and EdX (4.79) do not offer courses in Arabic, so they are used by individuals who master English language to the level they can take course in it.

Participants of the study were asked to select the reason (s) behind their attending MOOCs. Figure 6 shows that the main reasons behind enrolling in MOOCs were: learn new things, MOOCs are interesting, need credentials for my $\mathrm{CV}$.

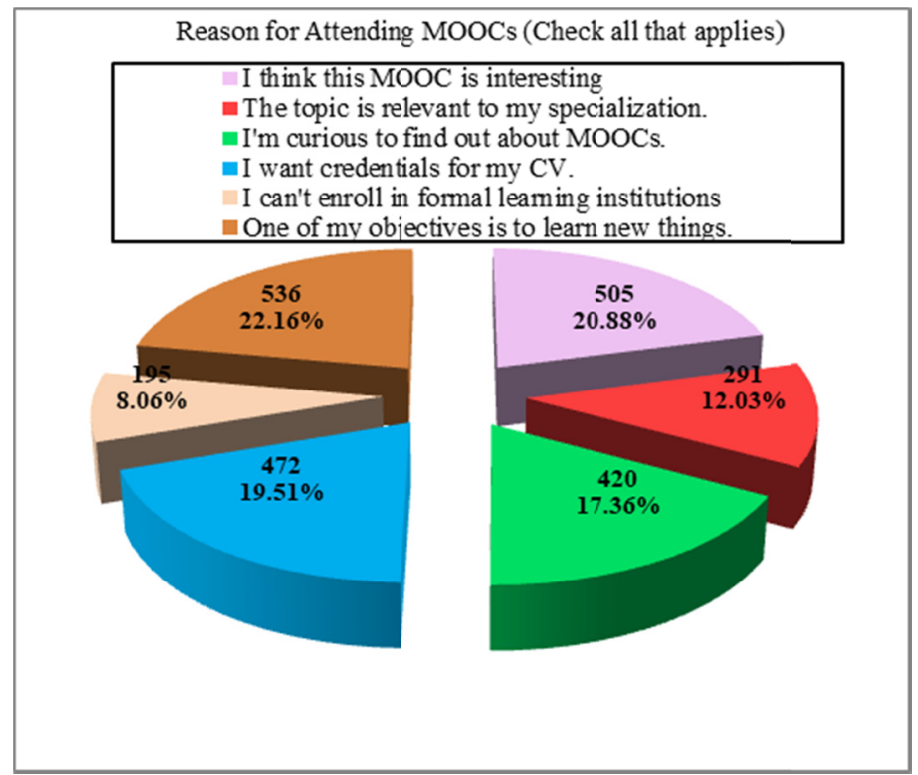

Figure 6. Reason(s) for enrolling in MOOCs

\subsection{Instrumentation}

To get a comprehensive view of learners' perceptions on MOOCs, participants were asked to fill in a web-based survey that consisted of 4 parts. Part one was meant to collect data related to gender, age, nationality, educational level, number of MOOCs previously completed, MOOC platforms previously used, reason(s) for enrolling in MOOCs. Part 2 was to assess participants' satisfaction with their learning experience in MOOCS. Part 3 dealt with learners' perceptions on the pluses and benefits of MOOCs. Part 4 dealt with barriers to MOOCs from the perspectives of participants. 
One open question was added to the survey to get a deeper understanding of the factors that appeal to learners in MOOCs, and the threats or challenges that hold them from enrolling or completing MOOCs. This open question was: "Evaluate your MOOC experience, what are the main pluses and minuses?" A total number of 821 participants filled in the survey.

\subsubsection{Instrumentation Validity}

A pilot test of the survey was conducted prior to its administration and validity was assessed. A panel of three experts specialized in instructional technology and psychological measurement were asked to assess clarity, wordiness, balance, and relevance of the survey items. Based on feedback and responses from the validity panel, revisions to the instrument were made.

Internal validity of the survey was verified by calculating the correlation coefficient between each item and the sub-scale to which it belongs. Table 2 shows the internal validity of the survey items. Correlation coefficients ranged between 0.64 and 0.94 , and all were significant at the 0.01 level. The survey in its final form consisted of 3 sub-sections along with a section on demographics and participants' characteristics.

Table 2. Correlation coefficients between survey items and corresponding sub-scale

\begin{tabular}{|c|c|c|c|}
\hline Scale & Items & $\begin{array}{c}\text { Correlation Coefficient } \\
\text { (r) }\end{array}$ & P-value \\
\hline \multirow{7}{*}{ 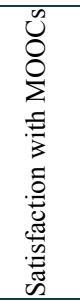 } & This MOOC contributed to my personal development. & 0.80 & 0.01 \\
\hline & I' $m$ happy with the level of interaction in this MOOC. & 0.91 & 0.01 \\
\hline & In the future, I will enroll again in such MOOCs. & 0.81 & 0.01 \\
\hline & This MOOC helped develop my skills. & 0.94 & 0.01 \\
\hline & I would recommend this MOOC to others. & 0.87 & 0.01 \\
\hline & Overall, I'm satisfied with this MOOC. & 0.94 & 0.01 \\
\hline & I enjoyed participating in MOOCs. & 0.90 & 0.01 \\
\hline \multirow{7}{*}{ 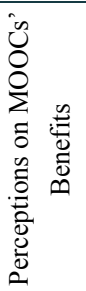 } & Using MOOCs expanded my knowledge at my specialization. & 0.78 & 0.01 \\
\hline & Participating in MOOCs developed my technological competency. & 0.90 & 0.01 \\
\hline & The discussion part of the MOOCs helped improve my communication skills. & 0.87 & 0.01 \\
\hline & The material I learned through MOOCs was valuable to me. & 0.84 & 0.01 \\
\hline & I think traditional courses are more helpful than MOOCs & 0.62 & 0.01 \\
\hline & It was easy to organize my learning activities during MOOCs. & 0.89 & 0.01 \\
\hline & The MOOCs structure and learning activities were flexible and supported my learning & 0.83 & 0.01 \\
\hline \multirow{8}{*}{ 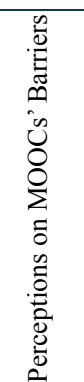 } & $\begin{array}{l}\text { Lacking the proficiency to use different tools and social media was a barrier to using } \\
\text { MOOCs. }\end{array}$ & 0.64 & 0.01 \\
\hline & I had problems accessing MOOCs materials due to unreliable internet connection. & 0.66 & 0.01 \\
\hline & The instructor was not there to help. & 0.85 & 0.01 \\
\hline & Not sufficient prior knowledge on the content was a barrier to learn. & 0.86 & 0.01 \\
\hline & I didn't have time to complete all required tasks and assignments. & 0.84 & 0.01 \\
\hline & The assignments were ambiguous. & 0.80 & 0.01 \\
\hline & I don't have the incentive to complete MOOCs. & 0.61 & 0.01 \\
\hline & I think I need someone to help me use MOOCs. & 0.84 & 0.01 \\
\hline
\end{tabular}

\subsubsection{Instrumentation Reliability}

The first sub-scale addressed learners' satisfaction with MOOCs' and was based on the satisfaction scale by Abdel-Maksoud (2018). It was modified to address MOOCs and consisted of 7 statements rated on a 5-point Liker scale ( $5=$ strongest agreement, $1=$ strongest disagreement) Cronbach's Alpha of this sub scale was 0.95 .

The second sub-scale examined participants' perceptions on MOOCs' drivers and was also based on Abdel-Maksoud (2018). It was modified for this study and consisted of seven statements, six of them were rated on a 5-point Likert scale (5=strongest agreement, $1=$ strongest disagreement). Cronbach's Alpha of this sub scale was 0.91. The statements in this sub-scale cover the areas of MOOCs' ease of use and usefulness.

The third sub-scale addressed learners' perceptions on barriers and challenges to MOOCs, and consisted of 7 statements rated on a 5 -point Likert scale ( $5=$ strongest agreement, $1=$ strongest disagreement). Cronbach's Alpha of this sub scale was 0.88 . The statements in this sub-scale cover the areas of technology proficiency, internet connection, time constraints, prior knowledge, instructor presence and help, assignments and tasks, lack of 
incentives. Cronbach's Alpha for the survey as a whole was 0.89 . Table 3 shows reliability statistics for the survey and its sub-scales. All alpha values were high, which indicates that the scale is highly reliable.

Table 3. Reliability statistics of the survey and its sub-scales

\section{Results}

\begin{tabular}{lcc}
\hline Scale & Items & Cronbach's Alpha \\
\hline Satisfaction with MOOCs & 7 & 0.95 \\
Perceptions on MOOCs' Drivers & 7 & 0.91 \\
Perceptions on MOOCs' Barriers & 8 & 0.88 \\
Survey & 22 & 0.89 \\
\hline
\end{tabular}

The results of the study will be described and discussed in the same order of the research questions.

\subsection{Satisfaction in MOOCs}

$\mathrm{T}$ answer the first research question: "How satisfied are Arab learners with their MOOC experience?" responses to the sub-scale "MOOC Satisfaction" were analyzed. Table 4 shows learners' responses to each item of this sub-scale.

Table 4. Learners' satisfaction in MOOCs

\begin{tabular}{|c|c|c|c|c|c|c|c|c|}
\hline \multirow[b]{2}{*}{ Satisfaction with MOOCs } & \multicolumn{5}{|c|}{ Response } & \multirow[b]{2}{*}{$\stackrel{\text { चี }}{\sum_{\Sigma}^{ \pm}}$} & \multirow[b]{2}{*}{$\%$} & \multirow[b]{2}{*}{ 泀 } \\
\hline & 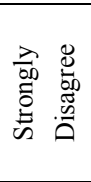 & 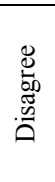 & $\begin{array}{l}\overline{\widetilde{E}} \\
\text { Z } \\
\text { Z }\end{array}$ & 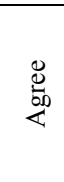 & 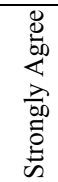 & & & \\
\hline MOOCs contributed to my personal development. & 21 & 35 & 179 & 229 & 357 & 4.05 & $81.10 \%$ & 6 \\
\hline I'm happy with the level of interaction in MOOCs. & 15 & 52 & 182 & 248 & 324 & 3.99 & $79.83 \%$ & 7 \\
\hline In the future, I will enroll again in such MOOCs. & 12 & 10 & 66 & 166 & 567 & 4.53 & $90.60 \%$ & 2 \\
\hline This MOOC helped develop my skills. & 14 & 37 & 125 & 235 & 410 & 4.21 & $84.12 \%$ & 4 \\
\hline I would recommend MOOCs to others. & 13 & 12 & 71 & 144 & 581 & 4.54 & $90.80 \%$ & 1 \\
\hline Overall, I'm satisfied with my MOOC experience. & 15 & 19 & 94 & 217 & 476 & 4.36 & $87.28 \%$ & 3 \\
\hline I enjoyed participating in MOOCs. & 16 & 26 & 143 & 281 & 355 & 4.14 & $82.73 \%$ & 5 \\
\hline Total & & & & & & 4.24 & $85.25 \%$ & \\
\hline
\end{tabular}

On a 5-point Liker scale (5=strongest agreement, $1=$ strongest disagreement), learners' mean satisfaction with MOOCs was 4.24 , which means that they were highly satisfied with their MOOC experience. $90.89 \%$ of participants would recommend MOOCs to others, and $90.84 \%$ of them would enroll again in MOOCs. The least item that got agreement on this sub-scale was item number 2: "I'm happy with the level of interaction in MOOCs.

\subsection{MOOCs Drivers and Benefits}

To answer the second research question:" What are the drivers (benefits) of MOOCs from the perspective of Arab learners?" responses to the sub-scale "Perceptions on MOOCs Benefits" were analyzed. Table 5 shows respondents' means on each item of the sub-scale. 
Table 5. Learners' perceptions on MOOCs' drivers

\begin{tabular}{|c|c|c|c|c|c|c|c|c|}
\hline \multirow[b]{2}{*}{ Perceptions on MOOCs' Drivers } & \multicolumn{5}{|c|}{ Response } & \multirow[b]{2}{*}{$\stackrel{\Xi}{\Xi}$} & \multirow[b]{2}{*}{ 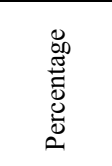 } & \multirow[b]{2}{*}{ 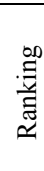 } \\
\hline & 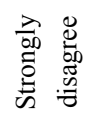 & 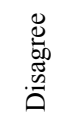 & 苛 & 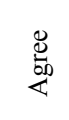 & 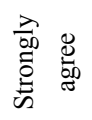 & & & \\
\hline Participating in MOOCs expanded my knowledge at my specialization. & 35 & 49 & 169 & 228 & 340 & 3.96 & $79.22 \%$ & 4 \\
\hline Participating in MOOCs developed my technological competency. & 26 & 43 & 180 & 240 & 332 & 3.99 & $79.71 \%$ & 3 \\
\hline The discussion part of the MOOCs helped improve my communication skills. & 51 & 89 & 215 & 217 & 249 & 3.64 & $72.76 \%$ & 6 \\
\hline The material I learned through MOOCs was valuable to me. & 15 & 27 & 121 & 264 & 394 & 4.21 & $84.24 \%$ & 1 \\
\hline I think traditional courses are more helpful than MOOCs & 219 & 203 & 182 & 92 & 125 & 2.64 & $52.72 \%$ & 7 \\
\hline It was easy to organize my learning activities during MOOCs. & 18 & 69 & 225 & 235 & 274 & 3.83 & $76.52 \%$ & 5 \\
\hline $\begin{array}{l}\text { The MOOCs structure and learning activities were flexible and supported my } \\
\text { learning }\end{array}$ & 14 & 29 & 162 & 237 & 379 & 4.14 & $82.85 \%$ & 2 \\
\hline Total & & & & & & 3.77 & $75.43 \%$ & \\
\hline
\end{tabular}

On a 5-point Liker scale (5=strongest agreement, $1=$ strongest disagreement), learners' mean perceptions on MOOC benefits was 3.77, which means that learners moderately perceived MOOCs to be useful. $84.24 \%$ of participants agreed that the material they learned in MOOCs was valuable to them. $82.85 \%$ of participants agreed that the MOOC structure and learning activities were flexible, and supported their learning.

\subsection{MOOCs Barriers}

To answer the third research question: "What are the main barriers to MOOCs from the perspective of Arab learners?", responses to the sub-scale "Barriers to MOOCs" were analyzed. Table 6 shows responses on each item of this sub-scale.

Table 6. Learners' perceptions on MOOCs' barriers

\begin{tabular}{|c|c|c|c|c|c|c|c|c|}
\hline \multirow[b]{2}{*}{ Perceptions on MOOCs' Barriers } & \multicolumn{5}{|c|}{ Response } & \multirow{2}{*}{ 一胥 } & \multirow[b]{2}{*}{$\%$} & \multirow[b]{2}{*}{$\frac{\infty}{\mathscr{\Xi}}$} \\
\hline & 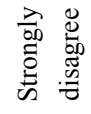 & 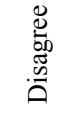 & $\begin{array}{l}\bar{\Xi} \\
\bar{\Xi} \\
\bar{Z}\end{array}$ & 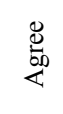 & 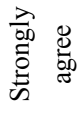 & & & \\
\hline $\begin{array}{l}\text { Lacking the proficiency to use different tools and social media was a barrier to } \\
\text { using MOOCs. }\end{array}$ & 317 & 147 & 179 & 92 & 86 & 2.37 & $47.41 \%$ & 3 \\
\hline $\begin{array}{l}\text { I had problems accessing MOOCs materials due to unreliable internet } \\
\text { connection. }\end{array}$ & 264 & 143 & 175 & 108 & 131 & 2.63 & $52.67 \%$ & 1 \\
\hline The instructor was not there to help. & 348 & 157 & 182 & 75 & 59 & 2.20 & $43.92 \%$ & 4 \\
\hline Not having sufficient prior knowledge on the content was a barrier to learn. & 350 & 162 & 185 & 70 & 54 & 2.17 & $43.34 \%$ & 5 \\
\hline I didn't have time to complete all required tasks and assignments. & 246 & 145 & 207 & 130 & 93 & 2.61 & $52.18 \%$ & 2 \\
\hline The assignments were ambiguous. & 418 & 168 & 145 & 52 & 38 & 1.93 & $38.66 \%$ & 8 \\
\hline I don't have the incentive to complete MOOCs. & 439 & 145 & 117 & 58 & 62 & 1.98 & $39.51 \%$ & 7 \\
\hline I think I need someone to help me use MOOCs. & 340 & 196 & 186 & 52 & 47 & 2.11 & $42.22 \%$ & 6 \\
\hline Total & & & & & & 2.25 & $44.99 \%$ & \\
\hline
\end{tabular}

On a 5-point Liker scale ( $5=$ strongest agreement, $1=$ strongest disagreement), learners' mean perceptions on MOOC barriers was 2.25. Unreliable internet connection (52.67\%) and "Lack of time to complete all required tasks" (52.18\%) were the main barriers to MOOC from the perspective of Arab Learners.

\subsection{Factors Affecting Satisfaction in MOOCs}

To answer the fourth research question: "Are age, gender, academic level, and number of MOOCs previously completed, correlated with learners' satisfaction in MOOCs?" different statistical tests were run. First, to examine if gender had a significant effect on MOOC satisfaction, t-test was run. Table 7 shows the results of t-test. 
Table 7. Effect of gender on MOOC satisfaction

\begin{tabular}{ccccccc}
\hline \multirow{2}{*}{ Gender } & \multirow{2}{*}{$\mathrm{N}$} & \multirow{2}{*}{ Mean } & SD & \multicolumn{3}{c}{ T-test } \\
\cline { 5 - 7 } & & & & T-value & $\mathrm{DF}$ & P-value \\
\hline Male & 399 & 29.73 & 5.17 & \multirow{2}{*}{0.57} & 819 & 0.567 \\
Female & 422 & 29.94 & 5.50 & & & \\
\hline
\end{tabular}

Table 7 shows that there was no significant difference in MOOC satisfaction between males and females, $(t=0.57$, $p=0.0567$ ). Second, to examine if age had a significant effect on MOOC satisfaction, One-way ANOVA test was run. Table 8 shows the results of ANOVA test.

Table 8. Effect of age on MOOC satisfaction

\begin{tabular}{cccccc}
\hline & Sum squares & DF & Mean squares & F-value & P-value \\
\hline Between groups & 205.8485 & 3 & 68.62 & & \\
Within groups & 23188.93 & 817 & 28.38 & 2.42 & 0.065 \\
$\quad$ Total & 23394.78 & 820 & & & \\
\hline
\end{tabular}

As shown in Table $8,(\mathrm{f}=2.42, \mathrm{p}=0.065)$, which means that there was no difference in MOOC satisfaction that could be attributed to age.

To examine the effect of number of MOOCs previously completed on MOOC satisfaction, One-way Anova was run; Table 9 shows the results of ANOVA test.

Table 9. Effect of the number of MOOCs completed on MOOC satisfaction

\begin{tabular}{cccccc}
\hline & Sum square & DF & Mean square & F-value & P-value \\
\hline Between groups & 580.04 & 5 & 116.01 & & \\
Within groups & 22814.74 & 815 & 27.99 & 4.14 & 0.001 \\
$\quad$ Total & 23394.78 & 820 & & & \\
\hline
\end{tabular}

Table 9 shows that there is a significant difference in MOOC satisfaction, that could be attributed to the number of MOOCs previously completed. The more MOOCs completed the more satisfied in MOOC learners are.

To see if there is a significant difference in MOOC satisfaction due to Academic level, One-way Anova was run; Table 10 shows the results of ANOVA test.

Table 10. Effect of academic level on MOOC satisfaction

\begin{tabular}{cccccc}
\hline & Sum square & DF & Mean square & F-value & P-value \\
\hline Between groups & 17.0475 & 3 & 5.68 & & \\
Within groups & 23377.73 & 817 & 28.61 & 0.20 & 0.897 \\
Total & 23394.78 & 820 & & & \\
\hline
\end{tabular}

Table 10 shows that there is no significant difference $(f=0.20, p=0.897)$ in MOOC satisfaction that could be attributed to academic level.

\section{Discussion}

Arabic MOOCs platform are launched to make high quality education more accessible for the Arabic-speaking population. While MOOCs alone can't solve all the problems the educational system in the Arab region has, they certainly can be part of the solution. Raising awareness about MOOCs and understanding the factors that affect their adoption in the Arab region is needed to ensure that MOOCs can achieve their objectives. This study tries to fill in the gap in literature that dealt with MOOCs in the Arab region. The study employed a quantitative descriptive design to answer four main questions: How satisfied are Arab learners in MOOCs? What are the main drivers of MOOC adoption from the perspective of Arab learners? What are the main barriers of MOOC adoption 
from the perspective of Arab learners? Do factors like gender, age, academic level, number of MOOCs previously completed affect MOOC satisfaction?

Satisfaction is important for MOOC adoption and sustainability, research has shown that if learners are satisfied with their learning experience, they are more likely to persist. The participants in this study were 821, enrolled in at least one MOOC offered by one of the biggest Arabic MOOC platforms, Rwaq. Participants were highly satisfied with MOOCs. The majority (90\%) would recommend MOOCs to others, and would enroll again in MOOCs. Actually, $82 \%$ of participants expressed that they enjoyed participating in MOOCs.

The main drivers of MOOC adoption by the study sample were: the material I learned through MOOCs was valuable to me, the MOOCs structure and learning activities were flexible and supported my learning, participating in MOOCs developed my technological competency, participating in MOOCs expanded my knowledge at my specialization.

The main barriers of MOOC as reported by the sample of the study were: problems accessing MOOCs materials due to unreliable internet connection, not having time to complete all required tasks and assignments, lacking the proficiency to use different tools and social in MOOCs, and that the instructor was not there to help. MOOCs can provide high quality education for disadvantaged regions; still people in those regions need to have a reliable internet connection, and moderate to good technology competence to participate in MOOCs. In many parts of the Arab region, there is a problem in internet connection, only $40 \%$ of people there have internet access (Statista, 2019).

To get in-depth understanding of learners' perceptions on MOOCs, one open question was added to the survey. Participants were asked to evaluate their MOOC experience. As an answer to this question, participants wrote:

- Courses are varied and useful.

- I don't have problems, thanks to the MOOC providers.

- Need content in the form of pdf files so that we can refer to it especially with unreliable internet connection

- The only drawback is that we do not get feedback on our questions from the instructor.

- I don't have time to turn in assignments within the deadlines.

- Programming courses are rare on Arabic platforms.

- $\quad$ Very pleased with these courses, no problems at all.

- The poor network is my only problem.

- I am the last minute student but it was more than ok.

- $\quad$ Need accredited certificates

In general, learners' comments were favorable to MOOC, the main problem for many was internet connection, therefore, many requested that content should be available in pdf files. Another major problem for many was time constraints due to job and family considerations. Not getting timely feedback from the instructor was also a problem expressed by many learners. The fact that certificates are not accredited was discouraging for many learners. All these problems need to be resolved to expand MOOC adoption in the Arab region.

\section{Delimitations of the Study}

This study focused on the learners' perceptions of MOOCs and their satisfaction with their MOOC experience. Participants in this study were all from Arab countries, and Arabic is their native language. Participants were enrolled in one or more of the MOOCs provided by Rwaq platform. Further testing using other populations using other Arabic MOOC platforms would be necessary to confirm the findings reported here. Data were collected using the survey research method, so all data were self-reported by the participants, and therefore were subjective. Further studies are required to confirm the findings of this study.

\section{Acknowledgments}

The author would like to thank Rwaq platform for assisting in implementing this research instrumentation.

\section{References}

Abdel-Maksoud, N. F. (2018). The Relationship between Students' Satisfaction in the LMS "Acadox" and Their Perceptions of its Usefulness, and Ease of Use. Journal of Education and Learning, 7(2), 184-190. https://doi.org/10.5539/jel.v7n2p184

Abdel-Maksoud, N. F. (2019). Investigating the Effect of Blending MOOCs with Flipped Classroom on 
Engagement in Learning and Course Grades. International Educational Research, 2(2), 8-25. https://doi.org/10.30560/ier.v2n2p8

Adamopoulos, P. (2013). What makes a great MOOC? An interdisciplinary analysis of student retention in online courses. In Proceedings of Thirty Fourth International Conference on Information Systems, Milan 2013.

Baggaley, J. (2014). MOOC postscript. Distance Education, 35(1), 126-132. https://doi.org/10.1080/01587919.2013.876142

Barclay, C., \& Logan, D. (2013, December). Towards an understanding of the implementation \& adoption of massive online open courses (MOOCs) in a developing economy context. In the Proceedings of Annual Workshop of the AIS Special Interest Group for ICT in Global Development (Vol. 6, pp. 1-14).

Castillo, N. M., Lee, J., Zahra, F. T., \& Wagner, D. A. (2015). MOOCS for development: Trends, challenges, and opportunities. Information Technologies \& International Development, 11(2), 35-42.

Class Central. (2018). By the numbers: MOOCS in 2018. Retrieved from https://www.classcentral.com/report/mooc-stats-2018/

Downes, S. (2008). Places to go: Connectivism \& connective knowledge. Innovate: Journal of Online Education, 5(1), A6. Retrieved from https://nsuworks.nova.edu/innovate/vol5/iss 1/6

Downes, S. (2012). Connectivism and connective knowledge: Essays on meaning and learning networks. National Research Council Canada. Retrieved http://www.downes.ca/files/books/Connective_Knowledge-19May2012.pdf

Evans, B. J., Baker, R. B., \& Dee, T. S. (2016). Persistence patterns in massive open online courses (MOOCs). Journal of Higher Education, 87(2), 206-242. https://doi.org/10.1353/jhe.2016.0006

Fianu, E., Blewett, C., Ampong, G., \& Ofori, K. (2018). Factors Affecting MOOC Usage by Students in Selected Ghanaian Universities. Education Sciences, 8(2), 70. https://doi.org/10.3390/educsci8020070

Fidalgo-Blanco, Á., Sein-Echaluce, M. L., \& García-Peñalvo, F. J. (2016). From massive access to cooperation: lessons learned and proven results of a hybrid xMOOC/cMOOC pedagogical approach to MOOCs. International Journal of Educational Technology in Higher Education, 13(1), 24. https://doi.org/10.1186/s41239-016-0024-z

Fini, A. (2009). The technological dimension of a massive open online course: The case of the CCK08 course tools. International Review of Research in Open and Distance Learning, 10(5), 1-26. https://doi.org/10.19173/irrodl.v10i5.643

Fischer, G. (2014). Beyond hype and underestimation: Identifying research challenges for the future of MOOCs. Distance Education, 35(2), 149-158. https://doi.org/10.1080/01587919.2014.920752

Gameel, B. G., \& Wilkins, K. G. (2019). When it comes to MOOCs, where you are from makes a difference. Computers \& Education, 136, 49-60. https://doi.org/10.1016/j.compedu.2019.02.014

Hazlett, C. (2014). Queen Rania Foundation Launches Edraak, a MOOC Portal for the Arab World. Retrieved from http://blog.edx.org/queen-rania-foundation-launches-edraak

Hew, K. F., \& Cheung, W. S. (2014). Students' and instructors' use of massive open online courses (MOOCs): Motivations and challenges. Educational Research Review, 12, 45-58. https://doi.org/10.1016/j.edurev.2014.05.001

Hill, P. (2013, March 10). Emerging student patterns in MOOCs: A graphical view. E-Literate. Retrieved from http://mfeldstein.com/emerging_student_patterns_in_moocs_graphical_view

Hollands, F. M., \& Tirthali, D. (2014). MOOCs: Expectations and reality. Full report. Center for Benefit-Cost Studies of Education, Teachers College, Columbia University, NY. Retrieved from $\mathrm{http}: / / \mathrm{cbcse}$. org/wordpress/wp-conntent/uploads/2014/05/MOOCs_Expectations_and_Reality.pdf

Jordan, K. (2014). Initial trends in enrolment and completion of massive open online courses. The International Review of Research in Open and Distributed Learning, 15(1), 133-160. https://doi.org/10.19173/irrodl.v15i1.1651

Kennedy, J. (2014). Characteristics of massive open online courses (MOOCs): A research review, 2009-2012. Journal of Interactive Online Learning, 13(1), 1-15.

Kizilcec, R., \& Halawa, S. (2015). Attrition and achievement gaps in online learning. Paper presented at the In the Proceedings of the Second ACM Conference on Learning@ Scale, Vancouver, BC, Canada. 
https://doi.org/10.1145/2724660.2724680

Kop, R. (2011). The challenges to connectivist learning on open online networks: Learning experiences during a massive open online course. International Review of Research in Open and Distance Learning, 12(3), 19-38. https://doi.org/10.19173/irrodl.v12i3.882

Liyanagunawardena, T. R., (2012). Information Communication Technologies and Distance Education in Sri Lanka: A case study of two universities ( $\mathrm{PhD}$ thesis, University of Reading, Reading).

Liyanagunawardena, T. R., Adams, A. A., \& Williams, S. A. (2013). MOOCs: A systematic study of the published literature 2008-2012. The International Review of Research in Open and Distributed Learning, 14(3), 202-227. https://doi.org/10.19173/irrodl.v14i3.1455

Ma, L., \& Lee, C. S. (2019). Investigating the adoption of MOOCs: A technology-user-environment perspective. Journal of Computer Assisted Learning, 35(1), 89-98. https://doi.org/10.1111/jcal.12314

Milligan, C., Littlejohn, A., \& Margaryan, A. (2013). Patterns of engagement in connectivist MOOCs. MERLOT Journal of Online Learning and Teaching, 9(2), 149-159. Retrieved http://jolt.merlot.org/vo19no2/milligan_0613.htm

Ng, A., \& Widom, J. (2014). Origins of the modern MOOC (xMOOC). In F. M. Hollands, \& D. Tirthali (Eds.), MOOCs: Expectations and reality. Full report (pp. 34e41). New York, USA: Center for Benefit-Cost Studies of Education. Teachers College. Columbia University. Retrieved from http://cbcse.org/wordpress/wp-content/uploads/2014/05/MOOCs_Expectations_and_Reality.pdf

Pappano, L. (2012). The Year of the MOOC. The New York Times, 2(12), 2012.

Pirkle, H. (2014). Arabic MOOC platform Edraak launches to bring quality education to the region. In Wamda Blog, June 15, 2014. Retrieved from http://www.wamda.com/2014/06/first-arabic-mooc-platform-launches -quality-education

Pursel, B. K., Zhang, L., Jablokow, K. W., Choi, G. W., \& Velegol, D. (2016).Understanding MOOC students: Motivations and behaviours indicative of MOOC completion. Journal of Computer Assisted Learning, 32(3), 202-217. https://doi.org/10.1111/jcal.12131

Selingo, J. (2014). Demystifying the MOOC. New York Times. Retrieved from http://www.nytimes.com/

Semenova, T. V., \& Rudakova, L. M. (2016). Barriers to taking massive open online courses (MOOCs). Russian Education and Society, 58(3), 228-245. https://doi.org/10.1080/10609393.2016.1242992

Siemens, G. (2012, July 25). MOOCs are really a platform [Blog post]. Elearnspace. Retrieved from http://www.elearnspace.org/blog/2012/07/25/moocs-are-really-a-platform/

Siemens, G. (2013, October). How MOOCs are derailing open education. Keynote address presented to the 25th ICDE World Conference, Tianjin. Retrieved http://www.icde.org/How+MOOCs+are+derailing+Open+Education\%3A+George+Siemens+ICDE+World + Conference+keynote.b7C_wJLMZ1.ips

Statista. (2019). Percentage of individuals using the internet worldwide in 2017, by region. Retrieved from https://www.statista.com/statistics/333879/individuals-using-the-internet-worldwide-region/

Veletsianos, G., \& Shepherdson, P. (2016). A systematic analysis and synthesis of the empirical MOOC literature published in 2013-2015. The International Review of Research in Open and Distributed Learning, 17(2). https://doi.org/10.19173/irrodl.v17i2.2448

Watson, S. L., Watson, W. R., Yu, J. H., Alamri, H., \& Mueller, C. (2017). Learner profiles of attitudinal learning in a MOOC: An explanatory sequential mixed methods study. Computers \& Education, 114, 274-285. https://doi.org/10.1016/j.compedu.2017.07.005

\section{Copyrights}

Copyright for this article is retained by the author(s), with first publication rights granted to the journal.

This is an open-access article distributed under the terms and conditions of the Creative Commons Attribution license (http://creativecommons.org/licenses/by/4.0/). 